\title{
Azurin: A Copper Protein Found in Bordetella
}

\author{
BY I. W. SUTHERLAND AND J. F. WILKINSON \\ Department of Bacteriology, University of Edinburgh
}

(Received 2 May 1962)

\begin{abstract}
SUMMARY
All strains of Bordetella pertussis, B. bronchiseptica and B. parapertussis tested, were found to contain a blue protein; this has been named 'Azurin'. It has been extracted from the cells of all three species and it has also been isolated from culture supernatant fluids of $B$. pertussis. The azurin was purified by chromatography on ion-exchange cellulose derivatives and obtained in physically pure form; the materials from each species were identical. In one strain of $\boldsymbol{B}$. bronchiseptica azurin comprised $0 \cdot 1 \%$ of the bacterial dry weight. Azurin is a water-soluble autoxidizable protein of high oxidation-reduction potential $(+395 \mathrm{mV}$.). It has an absorption maximum at $625 \mathrm{~m} \mu$ in the oxidized form, with a millimolar extinction coefficient of $3.5 \times 10^{3}$. It contains $0.45 \%$ copper which can be completely removed by dialysis against cyanide. The molecular weight is 14,600 $\left(S_{20, w}=1.58 \times 10^{-13}, D_{20, w}=10.6 \times 10^{-7}\right)$. Azurin can be reduced by cysteine, glutathione and other reducing agents; the blue colour disappears on reduction. Azurin undergoes reduction in the presence of concentrated cell-free extracts of $\boldsymbol{B}$. bronchiseptica and succinate, and is reoxidized on aeration.
\end{abstract}

\section{INTRODUCTION}

Blue and green metallo-protein complexes have been isolated from a number of widely differing sources in nature. Several of the blue copper proteins isolated have been shown to be phenol oxidases, but other compounds without apparent enzymic activities have also been discovered. A green pigment, termed desulphoviridin, was obtained from the obligate anaerobic bacteria Desulphovibrio desulphuricans by Postgate (1956), while a copper protein was found in the chloroplasts of Chlorella ellipsoidea and in higher plants and named plastocyanin (Katoh, 1960; Katoh \& Takamiya, 1961). A blue protein was first discovered in Pseudomonas aeruginosa some years ago (Verhoeven \& Takeda, 1956); it was since isolated as a blue watersoluble, copper-protein complex by Horio (1958a) and its physical and chemical properties investigated (Horio, 1958b; Coval, Horio \& Kamen, 1961). The presence of a blue protein in fractions obtained from Bordetella pertussis was first reported by Hammarsten, Palmstierna \& Meyer (1959). The present paper describes the preparation, purification and some properties of a blue protein present in the three species of the genus Bordetella. A preliminary account of part of this work has appeared (Sutherland \& Wilkinson, 1962).

\section{METHODS}

Organisms and methods of culture. The bacteria used were obtained from the National Collection of Type Cultures, Colindale, unless otherwise indicated. The strains used were: Bordetella pertussis, NCTC 8474, 4412 (obtained from Dr H. 
Billaudelle, Karolinska Institute, Stockholm), 4507 (isolated at the City Hospital, Edinburgh), and 364 (the original Phase IV strain of Leslie \& Gardner kindly provided by Dr Jean Dolby, Lister Institute, Elstree). Strain 364 was avirulent for mice and a further avirulent strain, $4507 \mathrm{Av}$, was obtained by repeated subculture of strain 4507. Two Bordetella parapertussis strains were NCTC 7385 and NCTC 8250. The $B$. bronchiseptica strains were NCTC 454, NCTC 8344, NCTC 8761 and NCTC 8762, strain BR/1 (isolated in the Bacteriology Department, Edinburgh University) and strain 8759 (obtained from Dr A. P. Maclennan, Microbiological Research Establishment, Porton).

Media. Virulent Bordetella pertussis strains were grown in the tris + resin liquid medium described in an earlier paper (Sutherland \& Wilkinson, 1961). Other species were grown in a medium which contained (quantities/l. medium): Casamino acids (Difco technical) $4.0 \mathrm{~g}$.; sodium glutamate, $4.0 \mathrm{~g}$.; $\mathrm{KH}_{2} \mathrm{PO}_{4}, 0.1 \mathrm{~g}$.; $\mathrm{MgCl}_{2}, 6 \mathrm{H}_{2} \mathrm{O}$, 0.08 g.; $\mathrm{FeSO}_{4}, 7 \mathrm{H}_{2} \mathrm{O}, 0.002$ g.; $\mathrm{CuSO}_{4}, 5 \mathrm{H}_{2} \mathrm{O}, 0.004$ g.; $\mathrm{CaCl}_{2}, 0.01$ g.; yeast extract $200 \mathrm{ml}$. The yeast extract was prepared by the method of Cohen \& Wheeler (1946). The medium was adjusted to $\mathrm{pH} 7 \cdot 0$ with $\mathrm{N}-\mathrm{NaOH}$, distributed in $250 \mathrm{ml}$. quantities into $500 \mathrm{ml}$. Ehrlenmeyer flasks and sterilized by autoclaving at $120^{\circ}$ for $15 \mathrm{~min}$. After inoculation the flasks were incubated at $37^{\circ}$ and shaken at approximately 100 oscillations/min. on a reciprocating shaker (Distillers Company Ltd, Epsom). The cultures of $\boldsymbol{B}$. bronchiseptica, B. parapertussis and $\boldsymbol{B}$. pertussis were incubated for 24, 48 and $72 \mathrm{hr}$., respectively. The bacteria were harvested by centrifugation at about $5000 \mathrm{~g}$ for $30 \mathrm{~min}$. in a MSE refrigerated centrifuge, and stored unwashed at $-40^{\circ}$ until required.

Absorption spectra. A Unicam SP 500 spectrophotometer with $1 \mathrm{~cm}$. light path was used.

Total nitrogen. Nitrogen was determined by the micro-Kjeldahl method, the ammonia being trapped in boric acid and estimated colorimetrically with Nessler reagent.

Paper chromatography. Two-dimensional paper chromatography was used to identify the amino acids in protein hydrolysates. Whatman No. 1 paper sheets were run for $18 \mathrm{hr}$. with $80 \%(\mathrm{w} / \mathrm{v})$ phenol containing $0 \cdot 3 \%(\mathrm{v} / \mathrm{v})$ ammonia. They were then dried, rotated through $90^{\circ}$ and run for $24 \mathrm{hr}$. with butanol + acetic acid + water $\left(4+1+5\right.$ by vol.). All chromatograms were run at $25^{\circ}$. Amino acid spots were detected with ninhydrin.

Buffer solutions. All salts used were analytical grade reagents. The $\mathrm{pH}$ values were read on a Pye 'Dynacap' $\mathrm{pH}$ meter.

Krebs-Ringer solution. This had the following composition (g. $/ 100 \mathrm{ml}$. solution): $\mathrm{NaCl}, 0.9 ; \mathrm{KCl}, 0.04 ; \mathrm{MgSO}_{4}, 7 \mathrm{H}_{2} \mathrm{O}, 0.04 ; \mathrm{NaH}_{2} \mathrm{PO}_{4}, 2 \mathrm{H}_{2} \mathrm{O}, 0.39 ; 0.4 \mathrm{ml}$. $\mathrm{N}-\mathrm{HCl}$.

Measurement of oxidation-reduction potentials. These were determined potentiometrically by the method of Gibson (1961) in an atmosphere of oxygen-free nitrogen.

Concentration of solutions of heat-labile substances. Bacterial extracts and other protein-containing solutions were concentrated by the method of Palmstierna (1960), by using a form of carboxymethyl cellulose known as 'courulose' (British Celanese Ltd, Coventry), Alternatively, polyethylene glycol of molecular weight about 6000 was used according to the method of Kohn (1959). Both methods were satisfactory, the first being preferable when it was necessary to concentrate large volumes. 
RESULTS

Extraction of blue protein

Washings of the frozen Bordetella pertussis organisms in distilled water, or in Krebs-Ringer solution were blue in colour, but no coloured material was observed in washings from organisms of the other two species. This was probably because they were less easily lysed by the freezing and subsequent thawing. Several extraction procedures were investigated; the following routine was found to be applicable to all the species which were examined. The frozen bacteria (equivalent to about $50 \mathrm{~g}$. dry weight, obtained from $30 \mathrm{l}$. of medium), were suspended in one l. KrebsRinger solution to which $0 \cdot 1 \mathrm{M}$-urea had been added. The suspension was stirred at $0^{\circ}$ for $30 \mathrm{~min}$. by a high-speed stirrer, followed by centrifugation at $c .25,000 \mathrm{~g}$ for $60 \mathrm{~min}$. in the model L preparative Spinco ultracentrifuge. The supernatant fluid was stored in the cold and the bacterial deposit was extracted with a further $500 \mathrm{ml}$. of Krebs-Ringer solution containing urea. After centrifugation, as before, the supernatant fluid was again retained while the bacteria were suspended in $250 \mathrm{ml}$. distilled water, frozen and thawed. The viscous suspension was stirred as above, then centrifuged. The organisms were extracted with a further sample of distilled water, removed by centrifugation and discarded. The four extracts were pooled to give a viscous, opalescent solution; it was dark, greenish blue in colour. This solution was dialysed against cold running tap-water for $8 \mathrm{hr}$., then concentrated until the volume was about $100 \mathrm{ml}$. The extract was centrifuged at $100,000 \mathrm{~g}$ for $15 \mathrm{~min}$. in the ultracentrifuge. The deposit was washed with a small volume of distilled water, recentrifuged and discarded, the supernatant fluid being added to the initial solution. The coloured solution was dialysed against phosphate buffer $(0.02 \mathrm{M}$ $\mathrm{KH}_{2} \mathrm{PO}_{4}+\mathrm{Na}_{2} \mathrm{HPO}_{4}$ ) for $24 \mathrm{hr}$. at $4^{\circ}$ with constant agitation. The non-diffusible material was applied to a column of DEAE cellulose equilibrated against the same buffer, and pumped through the column at a rate of $10 \mathrm{ml} . / \mathrm{hr}$. The column was then washed through with a further $20 \mathrm{ml}$. buffer, the washings being added to the original eluate. This was bright blue in colour and appeared to be considerably less viscous than the original solution. The blue eluate was concentrated and dialysed for $48 \mathrm{hr}$. against acetate buffer $(0.02 \mathrm{M}, \mathrm{pH} 4 \cdot 6)$. A variable amount of precipitate appeared at this stage and was removed by centrifugation at $100,000 \mathrm{~g}$ for $15 \mathrm{~min}$. The supernatant fluid was applied to a CM cellulose column in the sodium form, which had been thoroughly washed with the same acetate buffer. The coloured material was all adsorbed at the top of the column. The $\mathrm{pH}$ value was gradually increased, using a gradient of acetate buffer $(0.02 \mathrm{M}, \mathrm{pH} 516)$ and $200 \mathrm{ml}$. mixer volume, and fractions were collected in an automatic fraction collector. The flow rate of the buffer was adjusted to $10 \mathrm{ml} / \mathrm{hr}$. The blue material started to elute from the column at about $\mathrm{pH} \mathrm{5 \cdot 12.} \mathrm{After} \mathrm{the} \mathrm{complete} \mathrm{elution} \mathrm{of} \mathrm{the} \mathrm{blue} \mathrm{material,}$ the top of the column was reddish brown in colour, probably due to the retention of cytochromes or other haemoproteins. The fractions containing blue material were concentrated, dialysed against acetate buffer $(\mathrm{pH} 4 \cdot 6)$ and rechromatographed on CM Sephadex (Pharmacia, Uppsala) using the same conditions. The final product was concentrated, dialysed against glass-distilled water and either stored at, $-\mathbf{4 0}{ }^{\circ}$ or lyophilized.

In typical experiments with Bordetella bronchiseptica strain 8344, equiv. $50 \mathrm{~g}$. 
dry weight of bacteria yielded 50-55 mg. of purified blue material. Although strains 454 and 8761 yielded comparable amounts of the product, the other strains and species contained less blue pigment. The differences did not appear to be due to incomplete extraction of the pigment from the bacteria, as ultrasonic disintegration of the cells at the end of the extraction process, followed by the complete extraction cycle, yielded no further blue material. In $B$. pertussis cultures, the longer incubation period resulted in some autolysis, with consequent liberation of blue pigment into the surrounding medium. When supernatants fluids from $B$. pertussis cultures were dialysed, concentrated and treated in the same way as cell extracts, about $0.2 \mathrm{mg}$. blue material/1. supernatant fluid was recovered. However, no pigment was isolated from the supernatant fluids of cultures of the other two species, even after prolonged incubation. This was probably because of the different degrees of autolysis occurring in these Bordetella species.

\section{Properties of the blue protein}

The blue material was present in all strains of the three Bordetella species tested. It could be extracted from the bacteria with Krebs-Ringer solution alone but omission of the urea made it necessary to increase the number of extractions to five or six before all the pigment was removed from the cells. The blue material could also be obtained in the soluble fraction after ultrasonic disintegration of the bacteria. All the pigment was in the solution after ultra-centrifugation of the sonic extracts and none was associated with the sedimentable portion.

The final product from ion exchange chromatography was very soluble in distilled water and solutions up to $10 \%$ could be prepared. It was insoluble in chloroform, ether and ethanol.

Absorption spectrum. The absorption spectrum of the purified pigment from a pertussis strain is shown in Fig. 1. In the oxidized form, maxima were observed at $279 \mathrm{~m} \mu$ and $625 \mathrm{~m} \mu$, but the latter peak disappeared on reduction. The millimolar extinction coefficient at $625 \mathrm{~m} \mu$, calculated on the basis of the molecular weight given below, was $3.5 \times 10^{3}$. Table 1 gives the ratio of $\mathrm{E}_{625}$ to $\mathrm{E}_{\mathbf{2 8 0}}$ at various stages of purification. Attempts to raise this value by other methods of purification, such as electrophoresis or chromatography on other ion exchange materials, were unsuccessful.

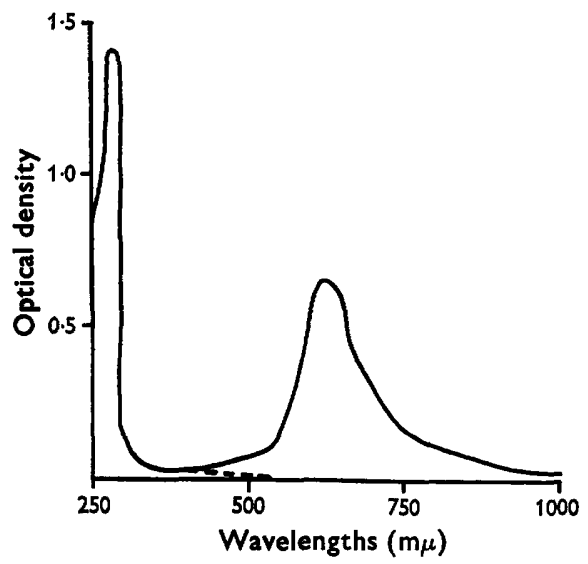

Fig. 1. Absorption spectrum of Bordetella blue protein 
Stability. The blue material was readily oxidized by air or oxygen. In the

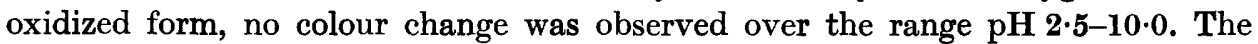
material was rapidly destroyed by boiling, the colour disappearing and a white precipitate of denatured protein being deposited. The pigment could be lyophilized to a blue powder which was completely soluble in distilled water.

Oxidation-reduction potential. After purification, the pigment was in the fully oxidized blue form. It could be reduced by a variety of reducing agents such as ascorbic acid, cysteine, sodium thioglycollate or sodium dithionite. The oxidationreduction potential of samples of the blue material $(5 \mathrm{mg}$.) was titrated potentiometrically and found to be $+395 \mathrm{mV}$ at $20^{\circ}$.

Table 1. Extinction ratios of blue protein at various stages of purification

(1) Crude, pooled extract after concentration and

$$
\begin{gathered}
\mathrm{E}_{6250 \mathrm{x}} / \mathrm{E}_{\mathbf{2 8 0}} \\
\mathbf{0 . 0 0 4}
\end{gathered}
$$
ultracentrifugation

(2) Eluate from DEAE cellulose column $\quad \mathbf{0 . 0 4 9}$

(3) As (2), after dialysis against acetate buffer ( $\mathrm{pH} \quad 0 \cdot 108$ 4.6) and removal of the precipitate

(4) Eluate from CM cellulose column $\quad \mathbf{0 . 3 4 3}$

(5) Eluate from CM Sephadex column $\quad \mathbf{0 . 4 6 5}$

Nitrogen content. Determination of the total nitrogen in samples of the pigment extracted from different strains revealed a content of $14.9-15.3 \%$. This was indicative of a protein and paper chromatography of acid hydrolysates showed the presence of the following amino acids : cystine, glycine, aspartic acid, serine, glutamic acid, lysine, arginine, threonine, alanine, tyrosine, phenylalanine, isoleucine, leucine. The possible presence of others, in amounts too small to be detected by the techniques used, was not excluded.

Molecular weight. The sedimentation coefficient of the blue protein from Bordetella bronchiseptica was determined in a series of runs in a Spinco model $\mathbf{E}$ analytical ultracentrifuge. The samples, at three concentrations $(0.15,0.4$ and $1.0 \%)$, were dissolved in phosphate buffer $(0 \cdot 2 \mathrm{M}, \mathrm{pH} 7 \cdot 0)$ and dialysed against the same buffer. The value obtained for the sedimentation coefficient extrapolated for zero protein concentration was $\mathrm{S}_{20, w}=1.59 \times 10^{-13}$.

The diffusion coefficient was obtained from a single run for $36 \mathrm{hr}$. in a modified Tiselius electrophoresis apparatus, at $20^{\circ}$, from which the resultant $D_{20, w}=10.6 \times$ $10^{-7}$. The partial specific volume was assumed to be 0.75 . This yields a molecular weight for the blue protein of 14,600 and a frictional ratio of $1 \cdot 28$. During sedimentation, a single peak was apparent and the blue peak moved with the Schlieren peak throughout the runs. Similar values were obtained for a run with a sample of Bordetella pertussis pigment.

Copper content. Spectrophotometric analysis indicated the presence of copper and the absence of iron, manganese and magnesium. Analysis of samples for their copper content was performed by activation analysis at the Atomic Energy Establishment, Wantage. The copper content of blue protein from four different strains is shown in Table 2 ; the mean value obtained from these results was $0 \cdot 447 \%$. This, allied to the molecular weight, indicates the presence of one copper atom per 
molecule of protein. No increase in copper content was obtained by dialysis against a copper sulphate solution followed by dialysis against distilled water to remove free copper ions. Dialysis against the chelating agent ethylenediamine tetra-acetic acid decreased the copper content of a sample of blue protein to $\mathbf{0 . 2 1 0} \%$, while dialysis against cyanide completely removed the copper.

Table 2. Copper content of blue protein from different Bordetella strains

$\begin{array}{lc} & \begin{array}{c}\text { Copper } \\ \text { content }(\%)\end{array} \\ \text { B. pertussis 4412 } & \mathbf{0 \cdot 4 3 6} \\ \text { B. pertussis 364 } & 0 \cdot 452 \\ \text { B. parapertussis 7385 } & 0 \cdot 448 \\ \text { B. bronchiseptica } 8344 & 0 \cdot 451\end{array}$

Metabolic activities. The blue protein was autoxidizable. A solution of the colourless reduced protein containing $100 \mu \mathrm{mole} / \mathrm{ml}$. was completely oxidized in 20-25 min. at $37^{\circ}$ when oxygen or air was passed through it. The rate of re-oxidation was very much greater, following the addition of small quantities of cell-free extracts of Bordetella species. The pigment was in the reduced form when the bacteria were harvested. This could be shown by visual examination of thick suspensions of Bordetella bronchiseptica cells immediately after harvesting; they were buff or pale pink in colour. However, when they were allowed to stand in air, or when air was passed through the suspensions, they rapidly turned greenish blue. This was seen most markedly in centrifuged bacterial deposits, the surface of which became blue while the underlying material remained pink. In the presence of succinate, the blue protein was rapidly reduced by cell-free extracts of Bordetella species.

Presence of similar pigments in other bacteria. Samples of bacteria of several other species were extracted by the method applied to Bordetella cells. Blue proteins, with properties very similar to those described for Bordetella material, were found in Alcaligenes faecalis NCTC 655, Alcaligenes denitrificans NCTC 8582 and Pseudomonas fuorescens strain 2. No trace of this type of protein was found in Escherichia coli B, Salmonella typhimurium strain 5, Bacillus megaterium strain 19, Chromobacterium violaceum NCTC 9757, Achromobacter anitratus NCTC 7844 or Moraxella bovis NCTC 8561.

\section{DISCUSSION}

The results described in this paper indicate that all three Bordetella species examined possess blue copper-proteins which are identical with respect to the tests that were made. We suggest the name azurin for this protein, as being in agreement with the nomenclature used for similar pigments, e.g. desulphoviridin (Postgate, 1956). The presence of copper-protein complexes of different function is widespread in nature. However, the only one of these compounds with any resemblance to azurin is the 'blue protein' isolated from Pseudomonas aeruginosa by Horio $(1958 a, b)$. This is remarkably similar in its redox potential $(+390 \mathrm{mV})$, the amended molecular weight of 14,600 (Coval, Horio \& Kamen, 1961) and in the presence of one atom of copper per molecule. Further, the 'blue protein' of $\boldsymbol{P}$. aeruginosa can be purified by the method outlined for Bordetella azurin. A further similarity lies in the report that the Pseudomonas protein, like azurin, can be freed from copper by 
dialysis against cyanide solution at neutral pH (Horio, Sekuzu, Higashi \& Okunuki, 1961). In both cases, the copper could be restored by dialysis against copper sulphate solution. This property is common to several copper-protein complexes (Westerfeld, 1961). There is one difference in the reported properties; Horio (1958a) stated that the 'blue protein' was not autoxidizable. However, when it is prepared from $\boldsymbol{P}$. aeruginosa by the method described above, the product is autoxidizable at a rate similar to that of azurin (Sutherland, unpublished results).

The continuous spectrum of azurin shows the absence of any Soret band similar to that found in desulphoviridin (Postgate, 1956). This indicates that the copper is not bound to the protein through a porphyrin molecule. The visible spectrum closely resembles that obtained for artificial copper-glycine complexes (Klotz, Faller \& Urquart, 1950) and it seems possible that the chromophore is a copperamino acid complex.

The function of azurin is uncertain. Its distribution appears to be somewhat limited in nature. The presence of azurin or similar pigments has only been found in the three genera Bordetella, Alcaligenes and Pseudomonas. No trace of similar compounds could be found in the species of Salmonella, Escherichia, Achromobacter or Bacillus tested. A relationship between the genus Alcaligenes and certain Pseudomonas species was indicated by Lysenko (1961) and it has been suggested that $A$. faecalis is related to B. bronchiseptica (Szturm \& Bourdon, 1948). However, it is difficult to see what, if any, is the common metabolic process in azurin-containing micro-organisms. One important difference between the metabolism of Pseudomonas species and that of the genus Bordetella is the ability of the former to grow anaerobically. The conditions of growth used by Horio (1958a), $100 \mathrm{l}$. unaerated medium in deep vessels, would indicate that growth was anaerobic. It therefore appears that the 'blue protein' was produced under anaerobic conditions, although the actual yield was not reported. Nor is there any quantitative result for the production of the protein under different oxygen tensions. Azurin, however, is obtained from highly aerated cultures and it is remarkable that some strains of $\boldsymbol{B}$. bronchiseptica contain as much as $0 \cdot 1 \%$ of their dry weight as this copper protein.

The 'blue protein' of Pseudomonas aeruginosa is thought to act as an alternative electron-transport system between a cytochrome of the $c$ type (Pseudomonas cytochrome 551) and cytochrome oxidase (Horio, 1958b). Initial investigations with azurin, using Bordetella bronchiseptica cell-free extracts and purified cytochromes suggest a similar function (Sutherland, unpublished results).

The authors wish to thank Professor E. Hammarsten and Dr H. Palmstierna for a gift of pertussis material; Dr H. J. Cruft for ultracentrifuge and electrophoresis studies and calculations; and Miss S. C. McCabe, Miss J. Thompson and Mr J. D. Caird for technical assistance. One of us (I.W.S.) is indebted to the University of Edinburgh for a Graduate Research Fellowship during part of this work. 


\section{REFERENCES}

Cohen, S. M. \& Wheeler, M. W. (1946). Pertussis vaccine prepared with phase-1 cultures grown in fluid medium. Amer. J. publ. Hlth, 36, 371.

Coval, M. L., Horio, T. \& Kamen, M. D. (1961). The amino acid composition of some bacterial haem proteins. Biochim. Biophys. Acta, 51, 246.

Gibson, J. (1961). Cytochrome pigments from the green photosynthetic bacterium, Chlorobium thiosulphatophilum. Biochem. J. 79, 151.

Hammarsten, E., Palmstierna, H. \& Meyer, E. (1959). Separation of acid polyelectrolytes and proteins in cellular extracts. J. biochem. microbiol. Tech. Eng. 1, 273.

Horio, T. $(1958 a)$. Terminal oxidation systems in bacteria. I. Purification of cytochromes from Pseudomonas aeruginosa. J. Biochem., Tokyo, 45, 195.

Horro, T. (1958b). Terminal oxidation systems in bacteria. II. Some physical and physiological properties of purified cytochromes of Pseudomonas aeruginosa. J. Biochem., Tokyo, 45, 267.

Horio, T., Sekuzu, I., Higashi, T. \& Okunuki, K. (1961). Cytochrome oxidases of Pseudomonas aeruginosa and ox-heart muscle, and their related respiratory components. In Haematin Enzymes, p. 302. Ed. Falk, J. E., Lemberg, R. \& Morton, R. K. Oxford: Pergamon Press.

KАтон, S. (1960). A new copper protein from Chlorella ellipsoidea. Nature, Lond. 186, 533.

Katoh, S. \& Takamtya, A. (1961). A new leaf copper protein 'plastocyanin', a natural Hill oxidant. Nature, Lond. 189, 665.

Klotz, I. M., Faller, I. L. \& URQUART, J. E. (1950). Spectra of copper complexes with some proteins, amino acids and related substances. J. phys. coll. Chem. 54, 18.

KонN, J. (1959). A simple method for concentrating fluids containing protein. Nature, Lond. 183, 1055.

Lysenko, O. (1961). Pseudomonas-An attempt at a general classification. J. gen. Microbiol. 25, 379.

Palmstierna, H. (1960). A method for concentrating solutions of high molecular weight compounds. Biochem. Biophys. res. Commn. 2, 53.

Postgate, J. R. (1956). Cytochrome $c_{3}$ and desulphoviridin; pigments of the anaerobe Desulphovibrio desulphuricans. J. gen. Microbiol. 14, 545.

Sutherland, I. W. \& Wilkinson, J. F. (1961). A new growth medium for virulent Bordetella pertussis. J. Path. Bact. 82, 481.

Sutherland, I. W. \& Wilkinson, J. F. (1962). Azurin, a blue bacterial protein. Biochem. $J$. (in the press).

SzTurm, S. \& Bourdon, D. (1948). Bacterium alcaligines fecalis et hemophilus bronchisepticus; caractères morphologiques et biochimiques. Ann. Inst. Pasteur, 75, 65.

VerHoeven, W. \& TAKEDA, Y. (1956). The participation of cytochrome $\mathrm{c}$ in nitrate reduction. In Inorganic Nitrogen Metabolism, p. 159. Ed. McElroy, W. D. \& Glass, B. Baltimore: The Johns Hopkins Press.

Westerfeld, W. W. (1961). Effect of metal-binding agents on metallo-proteins. Fed. Proc. 20, 158. 